\title{
The facilitative effects of shock and sensory deprivation on bar-pressing during extinction
}

\author{
ALAN R. MILLER, ROBERT A. STEWART AND VERNON L. KIKER \\ ANALYTIC BEHAVIORAL SYSTEMS AND CALIFORNIA STATE COLLEGE AT LOS ANGELES
}

\begin{abstract}
Sixteen male rats were run under four conditions, sensory deprived with shock, sensory deprived without shock, shock without sensory deprivation, and a no shock, no deprivation condition. All Ss were housed in Skinner boxes throughout the entire experiment to test the effects of these conditions on the number of bar presses prior to and during extinction. The results indicate that sensory deprivation and shock generate the highest bar-press rate prior to and during extinction, and that there is an interaction between shock and sensory deprivation.
\end{abstract}

Berlyne (1960) has pointed out that boredom, one of the conditions associated with sensory deprivation is accompanied by a high level of arousal. Geiwitz (1966) demonstrated that boredom is also associated with decreased cortical activity and an increase of sensorimotor or organismic activity. His conclusions seem to reconcile Berlyne's position with that of Hebb's (1955) who feels that boredom is accompanied by a lowering of arousal.

The purpose of this study is to investigate the effects of increased organismic activity created by sensory deprivation and shock on the number of barpresses during extinction. Jackett, Keith, \& Treat (1963) showed that rats raised in total darkness or constant bright light would go to the side of the $T$ maze which contained food and the more complex stimuli. They did not go to food if it was located on the visually less complex side of the maze. This seems to demonstrate that sensory constancy causes animals to choose stimuli which have a greater arousal potential. Berlyne, Koenig, \& Hirota (1966) illustrated that rats housed in a noisy environment were better reinforced when the stimuli were familiar rather than novel. The reverse was also true; animals housed in a quiet environment were better reinforced by novel stimuli. Miller, Kiker, \& Stewart (1967) demonstrated that animals housed in a sensory deprived environment bar-pressed more than Ss housed in the normal lab environment.

What these studies seem to indicate is that there is a relationship between Ss' arousal level and the type of stimuli which meets their arousal requirements.

If this is the case, Ss who live in sensory deprivation should bar-press more prior to and during extinction than $\mathrm{Ss}$ who are not sensory deprived. It further follows that Ss who receive shock in sensory deprivation should bar-press more than Ss who receive no shock. The last statement is based on the assumption that shock will replace the loss of sound and light. During extinction, the added factor of secondary reinforcement created through the association of shock and bar-pressing would also tend to enhance extinction scores.

\section{Method}

Subjects. Sixteen male albino rats, 80 days old at the beginning of the experiment, served as Ss.

Apparatus. Six Skinner boxes, four of which were enclosed in sound and light proof chambers, were used.

Procedure. Ss were allowed to train themselves. After training Ss were matched for bar-presses and randomly assigned to one of the following groups. The experiment was replicated until there were four Ss in each condition. Group 1 were sensory deprived and received shock (SSD). The second group were sensory deprived but received no shock (NSD). The third group received shock but were not sensory deprived (SND). Group 4 received neither shock nor sensory deprivation (NND).

At this point, all Ss lived in their respective conditions throughout the entire experiment. They had free access to water, and their drop pans were changed every two days at different hours. The only way the Ss could obtain food was by pressing the bar inside their boxes. After training all Ss were given two additional days of free responding to insure that their rates remained constant. On the third day a shock of 30 A was delivered through the paws of the SSD and SND groups each time they pressed down on the bar. The shock was delivered through a constant current shock source. A scrambler was not used; Ss merely closed the switch between the grids of the cage and the bar. When $S$ pressed the bar, the shock source meter indicated to $E$ that $S$ was receiving shock. There were random meter checks to insure that Ss didn't learn to avoid shock. Every day the shock was increased by 50 A until the current reached $1.03 \mathrm{~mA}$. After one day of responding at this level of shock, all feeders were shut off, but the SSD and SND groups still received shock whenever they pressed the bar. Ss were allowed to extinguish for a period of 24 h. Extinction scores were the number of bar-presses made within the $24 \mathrm{~h}$ period.

Results

Two analyses of variance were performed on the data. Analysis 1 was on the number of bar-presses for each group on the last day of the experiment, prior to the extinction phase. This was when the SSD and the SND groups were receiving $1.03 \mathrm{~mA}$ 
of shock. The $F$ values were as follows: For sensory deprivation/no sensory deprivation $F=31.45, \mathrm{df}=1 / 12$, $\mathrm{p}=.001$; for the shock/no shock condition $\mathrm{F}=15.68, \mathrm{df}=$ $1 / 12, p=.01$. The interaction was significant $(F=9.86$, $\mathrm{df}=1 / 12, p=.01$ ).

Analysis 2 was performed on the number of barpresses for the $24 \mathrm{~h}$ period after the feeders were shut off. This constitutes the extinction phase. The $F$ values were as follows: For sensory deprivation/no sensory deprivation $F=43.62, \mathrm{df}=1 / 12, \mathrm{p}=.001$; for the shock/no shock condition $F=19.93, \mathrm{df}=1 / 12, \mathrm{p}=.01$. The interaction was significant $(F=12.71, \mathrm{df}=1 / 12$, $\mathrm{p}=.01$ ).

\section{Discussion}

The rank order of scores for Analysis 1 were: SSD highest, NSD, SND and NND lowest. When sensory deprivation and shock are combined, bar-presses are highest; when they are both lacking, bar-presses are lowest. This could happen if sensory deprivation increased arousal and the effect of shock made up for the lack of sound and light. It also seems that shock by itself increases the number of bar-presses. The SND group had significantly higher scores than the NND group.

Analysis 2 follows our predictions that sensory deprivation also enhances bar-pressing during extinction. The rank order of scores for this phase were: SSD highest, NSD, SND, and NND lowest. The greater magnitude of the scoren lead w to belfeve

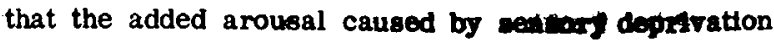
interacted with the frustration of belns triven off reinforcement. This is also demonetrated by the fact that the SSD group had the highent pores in this phase, even significantly higher scores than they had while on $100 \%$ food reinforcement. The same fact holds true for the NSD group. It is argesested that the effects of arousal on extinction be more closely studied with partial reinforcement scbecules, and with various levels of shock.

\section{References}

BERLYNE, D. E. Conflict, arousal and curiosity. New Yort: MoGrawHill, 1960.

BERLYNE, D. E., KOENIG, I. D. V., \& HIROTA, T. Novelty, arousal and the reinforcement of diversive exploration in the rat. J. comp. physiol Psychol, 1966, 62, 222-226.

GEIWITZ, P. J. Structure of boredom. J. pers soc. Psychol, 1966, 3, $592-600$.

HEBB, D. O. Drives and the C.N.S. (conceptual nervous system). Psychol Rev., 1955, 62, 243-254.

JACKETT, G., KEITH, L. P., \& TREAT, R، Food vs perceptual complexity as rewards for rats previously subjected to senery deprivetion. Science, 1963, 141, 518-520.

MILLER, A. R., KIKER, V. L., \& STEWART, R. A. A technique for studying the relationship between shock and bar-presces. Paper read at the West. Psychol Assoc. May, 1967, San Francisco, Calif. Note

1. The initial phases of this study were presented at the Westem Psychological Association, May 1967, San Francisco, Californic. 